R. TÂNGARI, Vera, G. CARDEMAN, Rogerio. Técnicas de simulação para analisar as transformações da forma urbana, da paisagem e do micro-clima em Vargem Grande, Rio de Janeiro/RJ, Brasil Thésis, Rio de Janeiro, v. 2, n. 2, p. 229-245, jul./dez. 2016

data de submissão: 10/05/2016 data de aceite: 26/08/2016

\section{Técnicas de simulação para analisar as transformações da forma urbana, da paisagem e do micro-clima em Vargem Grande, Rio de Janeiro/RJ, Brasil

\author{
Vera R. Tângari, Rogerio G. Cardema
}

Vera R. Tângari é doutora em Arquitetura e professora associada UFRJ/FAU-PROARQ | vtangari@uol.com.br

Rogerio G. Cardeman é doutor em Arquitetura e pesquisador UFRJ/FAU-PROARQ | r.cardeman@gmail.com

\section{Resumo}

Este estudo é parte de uma pesquisa abrangente e interdisciplinar sendo desenvolvida desde 2012 sobre a transformação da paisagem e forma urbana. Neste artigo, apresentamos a análise dos padrões de desenho urbano que estão sendo aplicados em uma região ambientalmente sensível, que está em rápido crescimento urbano, devido ao novo código de legislação urbanística, aprovado em 2009, ao aumento do valor da terra, à implementação de novos investimentos em transportes urbanos e da existência de grandes superfícies de espaços livres de edificação. Para realizar esse estudo, foi elaborada uma estratégia metodológica apoiada na integração entre aspectos geo-biofísicos, análise da legislação e dos lançamentos imobliários em curso, medições e levantamentos de campo, simulações de futuras ocupaçoes e estimativas habitacionais. Os resultados preliminares da pesquisa serão apresentados.

Palavras-chave: simulação, forma urbana, desenho urbano, unidades de paisagem, Rio de Janeiro.

\begin{abstract}
This study is part of a comprehensive and interdisciplinary research being developed since 2012 about landscape transformation and urban form. In this paper, we present the analysis of urban design patters being applied on an environmentally sensible region, which is undergoing rapid urban sprawl, due to urban legislation new code, land value increase, implementation of new investments in urban transportation and existence of large surfaces of open spaces. In order to make this study, we developed a methodological strategy supported by the integration of geo-bio-physical elements, analysis of the urban legislation and the real-state releases, measurements and field surveys, simulations of future occupations and housing estimates. The preliminary results of the research will be presented.
\end{abstract}

Keywords: simulation, urban form, urban design, landscape units, Rio de Janeiro.

\section{Resumen}

Este estudio forma parte de una investigación integral e interdisciplinario siendo desarrollado desde 2012 en la transformación del paisaje y la forma urbana. En este artículo, presentamos el análisis de las normas de diseño urbano que se están aplicando en una zona ambientalmente sensible, que está en rápido crecimiento urbano debido al nuevo código de la legislación urbanística, aprobado en 2009, al incremento en el valor del suelo, a la aplicación de nuevas inversiones en el transporte urbano y a la existencia 
de grandes áreas libres de espacios de construcción. Para realizar este estudio, hemos desarrollado una estrategia metodológica basada en la integración de los aspectos, el análisis de la legislación geo-biofísico y imobliários lanzan en curso, mediciones y estudios de campo, simulaciones futuras ocupaciones $y$ estimaciones de vivienda. Se presentarán los resultados preliminares de la investigación.

Palabras clave: simulación; la forma urbana, diseño urbano, unidades de paisaje, Rio de Janeiro.

\section{Introdução}

Este estudo é parte de uma pesquisa abrangente Ee interdisciplinar sendo desenvolvida desde 2012 sobre a transformação da paisagem e forma urbana (BUENO et al., 2012). Neste artigo, apresentamos a análise dos padrões de desenho urbano que estão sendo aplicados em uma região ambientalmente sensível, que está em rápido crescimento urbano, devido ao novo código de legislação urbanística, ao aumento do valor da terra, à implementação de novos investimentos em transportes urbanos e à existência de grandes superfícies de espaços livres de edificação. A área de estudo está localizada na zona oeste da cidade do Rio de Janeiro, ao longo da planície costeira com superfícies molhadas e solo frágil que se interpõem entre a Mata e o Oceano Atlântico (Figuras 1 e 2). A condição de fragilidade desse ambiente e a probabilidade de alteração permitida pela legislação urbanística foram descritas por diversos autores e justificam a análise desenvolvida (MACEDO, 1993, SCHLEE e TÂNGARI, 2008; MONTEZUMA e OLIVEIRA, 2010; NAME, MONTEZUMA E SESANA, 2011).

Atualmente, a área estudada tem cerca de 15.000 habitantes, está sob a regência de uma nova legislação urbanística (Plano de Estruturação Urbana da área das Vargens-Lei Complementar 104/2009) e em 2012 foi inaugurado o corredor de transporte em ônibus (BRT) denominado Transcarioca, cconforme pode ser observado na Figura 3.

Para entender os padrões urbanos existente, a ocupação futura e prever os impactos na paisagem e ambiente urbano, propusemos uma metodologia que integra campos disciplinares distintos e inclui as seguintes etapas: 1 - divisão em unidades e sub-unidades de paisagem, conforme descritas por Forman e Mezger (FORMAN, 1995, 2008 e METZGER, 2001); 2- seleção de pontos de medição para pesquisa de dados sobre temperatura e umidade; 3- identificação de glebas vazias ao longo dos principais eixos viários; 4- estudo dos códigos da legislação urbanística; 


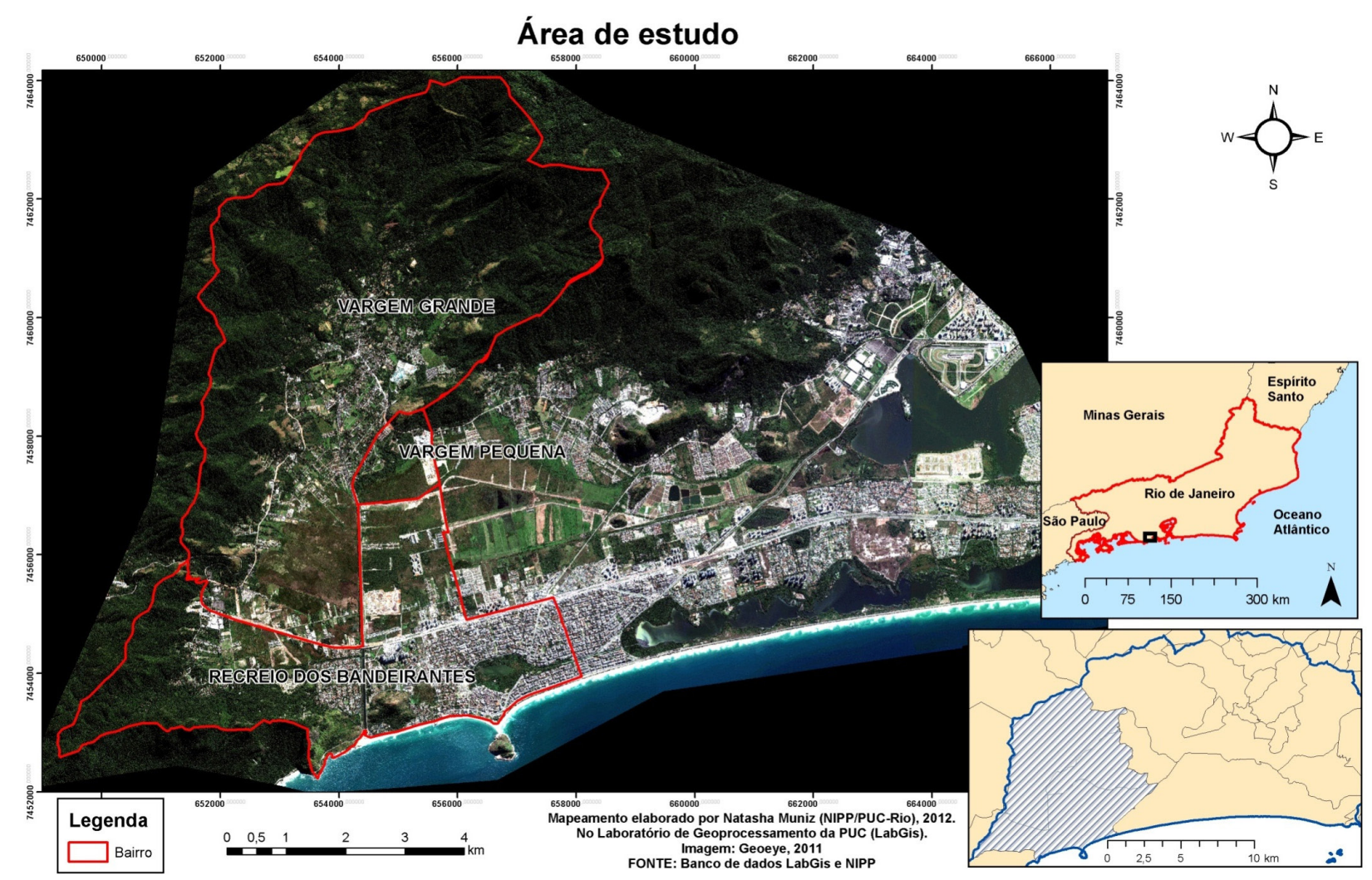

Figura 1

Localização da área de estudo

Mapeamento elaborado por Natasha Muniz (NIPP-PUC-Rio/LabGis), 2012, sobre Imagem Geoeye, 2011. Fonte de dados: LabGis e NIPP

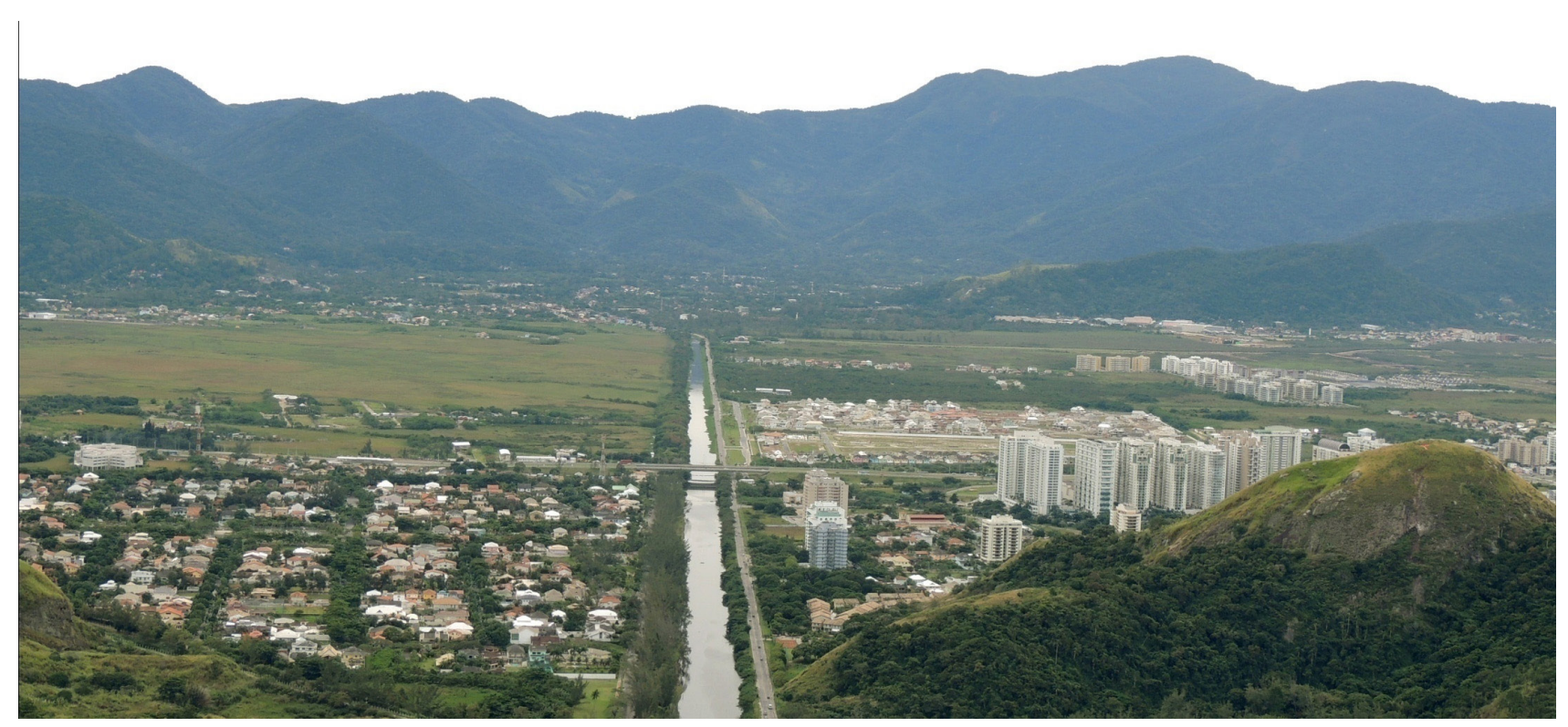

Figura 2

Aspecto geral da paisasgem da área de estudo

Fonte: Arquivo SEL-RJ e NIPP, 2013 


\section{Novos PEUs}

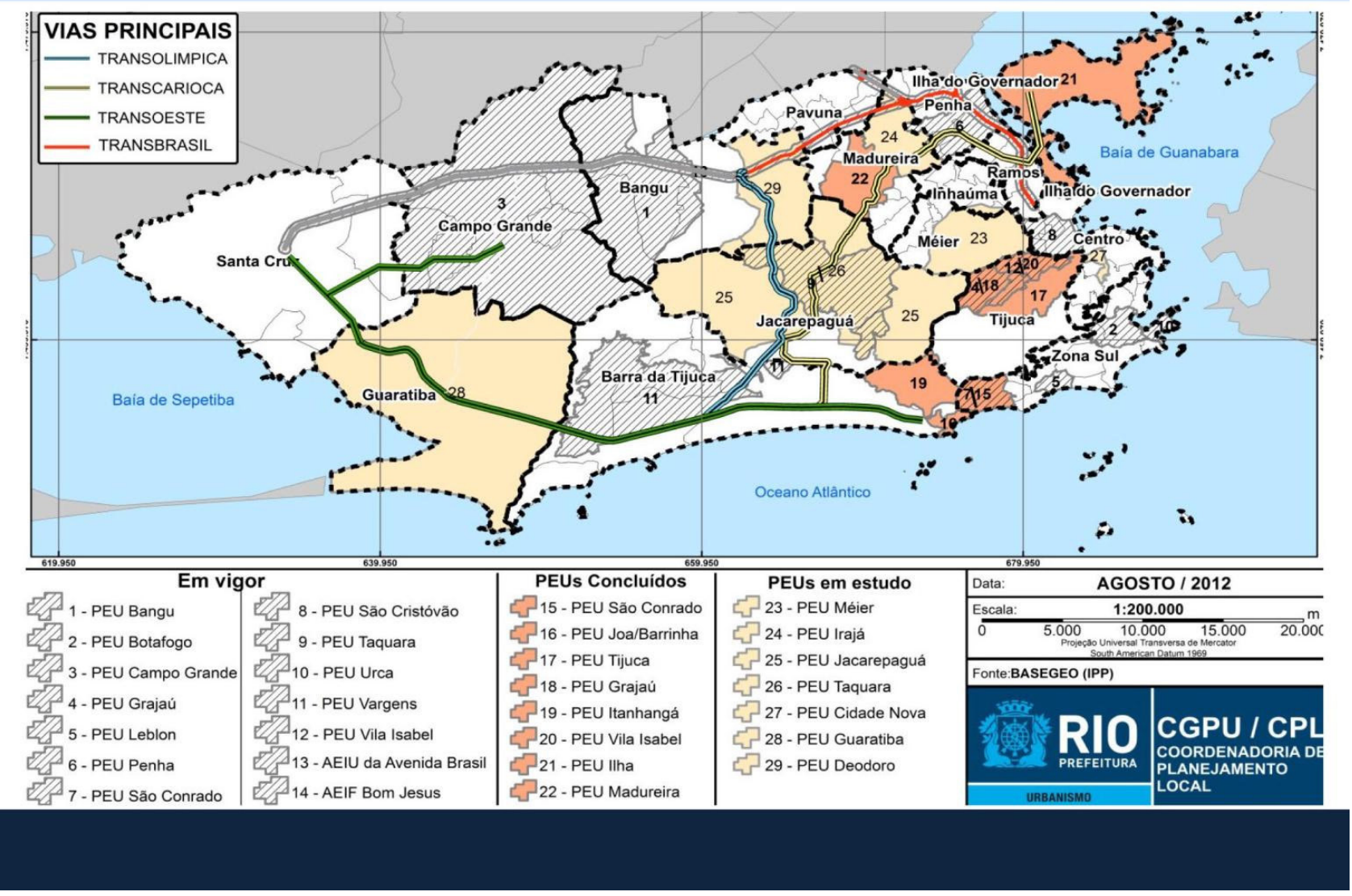

Figura 3

Plano de Estruturação Urbana e Corredores de Transporte

Fonte: PCRJ/Coordenadoria de Planejamento Local, 2012

5- identificação de padrões atuais de ocupação e de construção tipos adotados pelo mercado imobiliário; 6- simulações em 2D e em 3D da ocupação prevista para as glebas identificadas; 7- simulações microclimáticas de recortes específicos (PEZZUTO e SILVA, 2013). Nesse artigo, vamos enfocar as etapas 1, 3, 4, 5 e 6 e apresentar as premissas adotadas para desenvolver as simulações, incluindo os tipos construtivos, os padrões de desenho urbano, as estimativas de população e unidades habitacionais.

\section{Unidades e sub-unidades de paisagem}

A definição das Unidades de Paisagem, coordenada pela Prof. Dr. Rita Montezuma do POSGEO-UFF, foi o método de análise selecionado para a pesquisa. Para tanto, fez-se o estudo das características do terreno a partir da fisionomia estabelecendo inicialmente três grandes unidades de análise: serra, base das encostas da serra e baixada. A geomorfologia foi identificada como o elemento estruturante e condicionante das 
principais características do terreno, constituindo-se como o primeiro nível na hierarquia de divisão da paisagem. O segundo parâmetro adotado na identificação foram as características de cobertura do solo, uma vez que essas sintetizam o comportamento das condicionantes físicas e hidrológicas que vigoram em cada compartimento. Tanto a vegetação natural remanescente como coberturas secundárias desenvolvidas em áreas sem uso ou abandonadas, assim como áreas de cultivo, foram associadas às características do tecido urbano, concluindo o conjunto de critérios adotados na divisão da área de estudo. Essa classificação resultou em quatro Unidades, ordenadas no sentido nortesul, assim definidas: UP1, UP2, UP3 e UP4 (Figura 4).

A UP1 é a Unidade de Paisagem com baixa heterogeneidade e menor taxa de ocupação, por se tratar de área de abrangência do Parque Estadual da Pedra Branca, conforme já discutido anteriormente nesse artigo. A UP2 se destaca das demais nessa análise por ser a Unidade de Paisagem que apresenta maior heterogeneidade de tecido urbano consolidado (Figura 5). Com 22 delimitações (das quais 16 dentro da UP2), as áreas estruturadas por via de acesso privado e de média densidade de ocupação do lote foram as mais frequentemente identificadas. A presença de grandes glebas é consideravelmente elevada, totalizando 14 glebas de uso específico e 15 de sem uso aparente, demarcando igualmente uma área com elevado potencial de transformação e consolidação urbana. A UP3 corresponde à Unidade de Paisagem com baixa heterogeneidade por apresentar tecido urbano consolidado e grandes glebas ainda não ocupadas em áreas já urbanizadas. Suas características geobiofísicas a tornam mais sensível à ocupação. A UP4 se caracteriza por baixa heterogeneidade por apresentar tecido urbano consolidado e alto índice de verticalização.

Com base nos levantamentos de campo e registros em fotos áreas e na imagem satélite, tendo como segundo critério de maior relevância as características do tecido urbano - o qual espelha junto com a vegetação remanescente as condições vigentes no terreno, o resultado obtido para cada Unidade de Paisagem acima foi a divisão em duas subcategorias: Tecido Urbano Consolidado, onde ocorrem processos de loteamento e ocupação, e Tecido Urbano Não Consolidado, referente, de forma geral a áreas não parceladas, onde se verificam grandes glebas de uso específico (clubes, haras, dentre outros), terrenos em processos de terraplanagem ou setores com edificações isoladas, situados em sua maioria na área florestada. Nesse artigo, iremos detalhar a subcategoria Tecido Urbano Consolidado. 


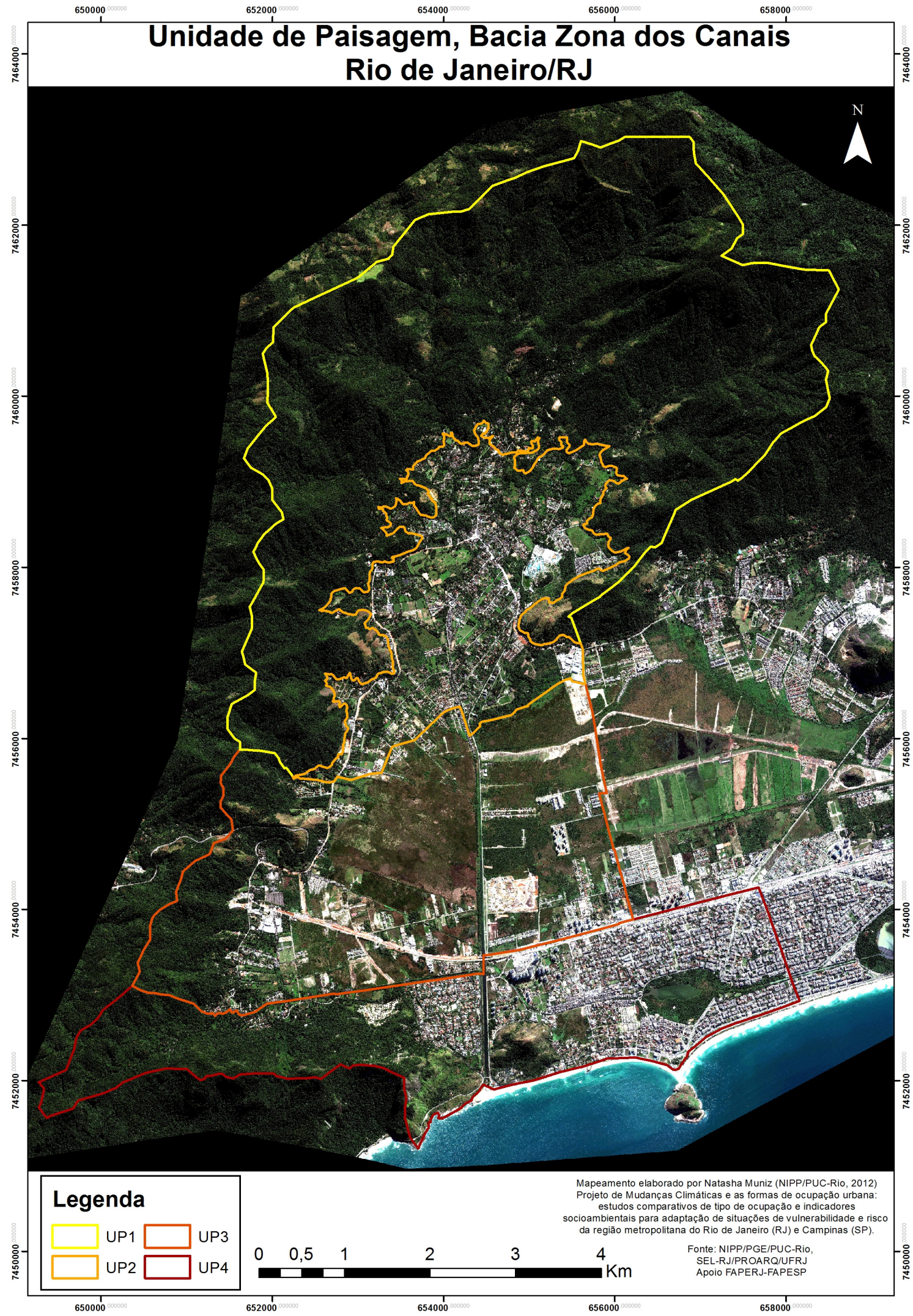

Figura 4

Area de estudo-Bacia dos Canais e delimitação das Unidades de Paisagem

Fonte: Grupo de Pesquisa CNPq NIPP/PUC-Rio, sobre imagem satélite Geoeye de 2011 
O Tecido Urbano Consolidado foi inicialmente diferenciado quanto à estrutura morfológica apresentada e quanto ao elemento principal que define essa estrutura, podendo ser norteado linearmente através de uma via, ou ortogonalmente, num sistema de quadras. Devido à intensa existência de ruas constituintes de condomínios fechados e que, portanto, apresentam acessibilidade reduzida, esse parâmetro foi considerado de importância fundamental para a caracterização da área de estudo. Foram acrescentadas as variáveis de densidade de ocupação do lote (baixa, média, ou alta), devido à necessidade de diferenciação dos tipos residenciais identificados. A densidade de ocupação aqui definida refere-se a densidade líquida, aplicandose a ocupação de lotes e quadras, retirando-se desse cálculo espaços livres públicos (ruas, praças, parques). No total obteve-se um quadro de classificação com 13 sub-unidades de paisagem na categoria de Tecido Consolidado (Tabelas 1 e 2).

TABELA 1

Categorização das sub-unidades de paisagem na categorização de Tecido Urbano Consolidado

\begin{tabular}{|c|c|c|}
\hline Via como elemento estruturador: & Quadra como elemento estruturador: & Grandes Glebas \\
\hline $\begin{array}{c}\text { - Via de acesso público (baixa densidade) } \\
\text { - Via de acesso público (média } \\
\text { densidade) } \\
\text { - Via de acesso público (alta densidade) } \\
\text { - Via de acesso privado (baixa densidade) } \\
\text { - Via de acesso privado (média } \\
\text { densidade) } \\
\text { - Via de acesso privado (alta densidade) } \\
\text { - Via sem acesso pavimentado } \\
\text { (comunidade) }\end{array}$ & $\begin{array}{c}\text { - Quadra de acesso público (média } \\
\text { densidade) } \\
\text { - Quadra de acesso público (alta densidade) } \\
\text { - Quadra de acesso privado (média } \\
\text { densidade) }\end{array}$ & $\begin{array}{c}\text { - Grandes glebas de uso } \\
\text { específico } \\
\text { - Glebas livres de } \\
\text { edificação }\end{array}$ \\
\hline
\end{tabular}

TABELA 2

Sub-unidades de paisagem identificadas dentro de cada Unidade de Paisagem

\begin{tabular}{|c|c|c|c|c|c|}
\hline \multirow{2}{*}{ Sub-unidades de paisagem } & \multicolumn{4}{|c|}{ Unidades de Paisagem } & \multirow[b]{2}{*}{ TOTAL } \\
\hline & UP1 & UP2 & UP3 & UP4 & \\
\hline Via de acesso público (baixa densidade) & 0 & 8 & 2 & 0 & 10 \\
\hline Via de acesso público (média densidade) & 0 & 8 & 2 & 0 & 10 \\
\hline Via de acesso público (alta densidade) & 0 & 1 & 0 & 1 & 2 \\
\hline Via de acesso privado (baixa densidade) & 0 & 6 & 1 & 0 & 7 \\
\hline Via de acesso privado (média densidade) & 0 & 16 & 5 & 1 & 22 \\
\hline Via de acesso privado (alta densidade) & 0 & 6 & 6 & 2 & 14 \\
\hline Via sem acesso pavimentado (comunidade) & 0 & 5 & 5 & 2 & 12 \\
\hline Quadra de acesso público (média densidade) & 0 & 0 & 0 & 2 & 2 \\
\hline Quadra de acesso público (alta densidade) & 0 & 0 & 0 & 1 & 1 \\
\hline Quadra de acesso privado (média densidade) & 0 & 0 & 0 & 1 & 1 \\
\hline Quadra de acesso privado (alta densidade) & 0 & 0 & 0 & 2 & 2 \\
\hline Grandes glebas de uso específico & 0 & 10 & 4 & 0 & 14 \\
\hline Glebas livres de edificação & 0 & 13 & 2 & 0 & 15 \\
\hline
\end{tabular}


A subunidade mais detectada foi a "Via de acesso privado (média densidade)", com 22 áreas identificadas, das quais 16 se encontram dentro da área da UP2, caracterizando o tecido urbano majoritariamente por condomínios residenciais fechados com densidade média de ocupação. No conjunto total, a maior heterogeneidade de subunidades foi encontrada na UP2 (Figura 5). A análise morfológica da paisagem reflete um sistema socioeconômico de dependência e subserviência entre classes sociais, interpretado através da incidência alta de comunidades de baixa renda nas diversas Unidades de Paisagem. Da mesma forma, a presença de grandes glebas é consideravelmente elevada, totalizando 14 glebas de uso específico e 15 de sem uso aparente. Desta forma se pode concluir que o caráter da região é de extrema heterogeneidade, predominando a via como elemento estruturador, sendo que na sua maioria é composta por áreas privadas.

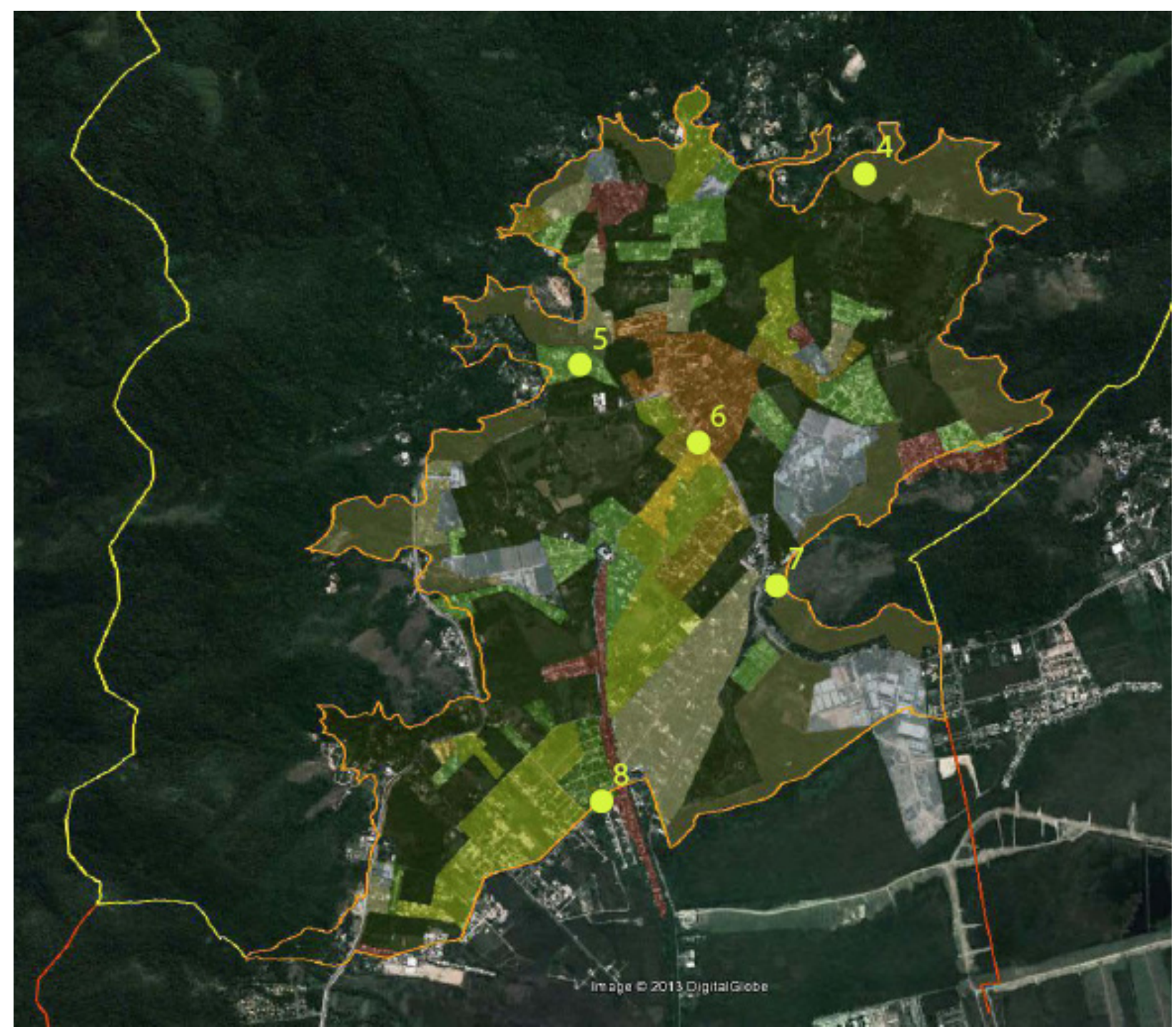

Figura 5

Sub-unidades de paisagem identificadas na UP2.

Mapeamento elaborado por Inês Isidoro sobre base Google Earth, 2013. Fonte: Grupo SEL-RJ 
Essa classificação nos auxiliou a selecionar as áreas prioritárias para início das simulações, tendo sido a UP2 escolhida para iniciarmos as análises das glebas vazias e passíveis de ocupação.

\section{Premissas para simulação: identifi- cação de glebas, legislação e tipos construtivos}

Tendo em vista a análise feita para as unidades e subunidades de paisagem, o passo seguinte foi verificar como a legislação urbanística, através do PEU-Plano de Estruturação Urbana de Vargens (Lei Complementar 104/2009), estabelecia a ocupação dos diversos setores no qual se divide e pode ser observado na Figura 6.

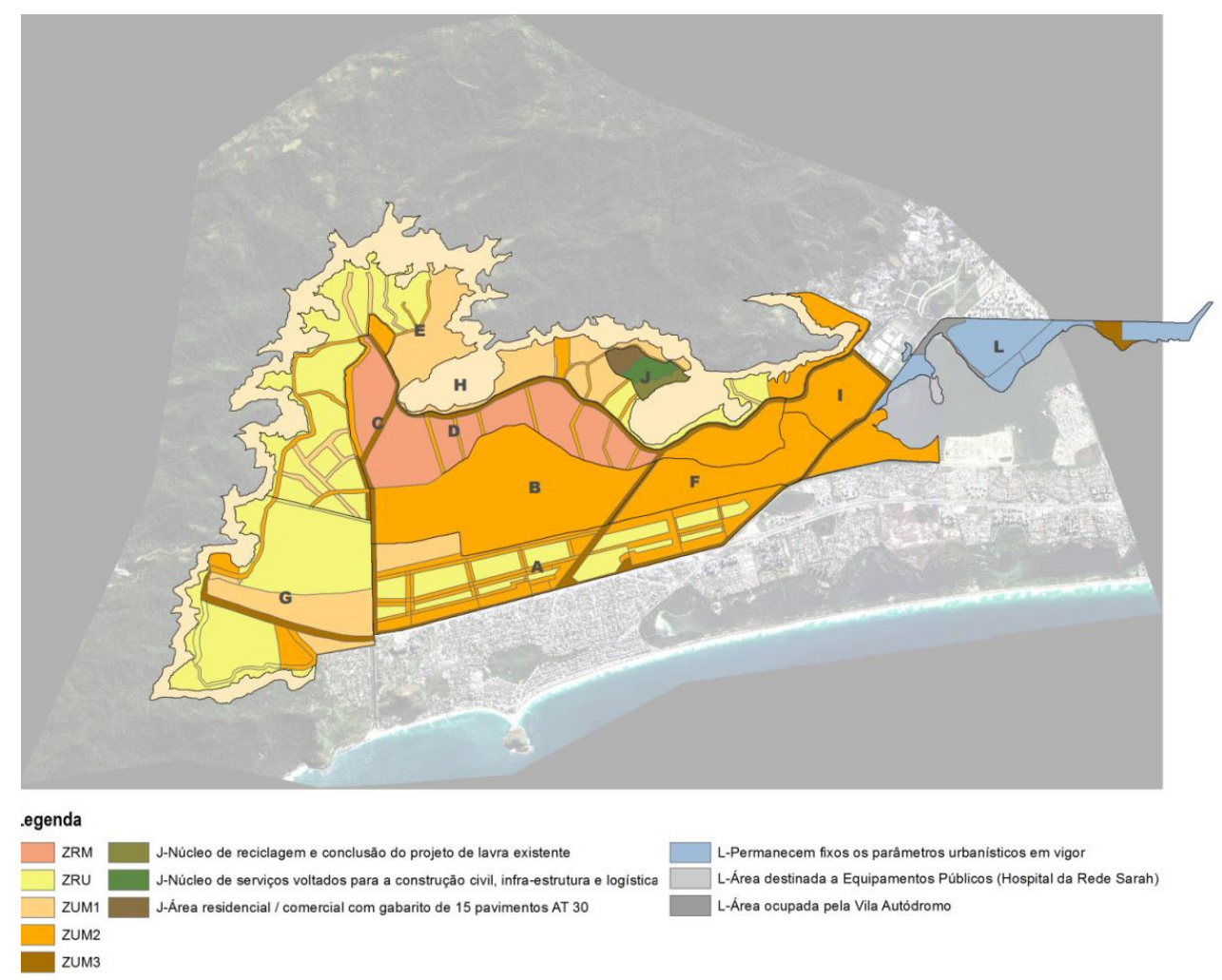

Figura 6

Zoneamento estabelecido pelo PEU das Vargens - LC 104/2009

Fonte: Desenho elaborado pela equipe SEL-RJ sobre Imagem Geoeye, 2011

Considerando a seleção da UP2 para início das simulações, observamos que sobre essa Unidade incide o setor $\mathrm{E}$, com Zonas de Uso Misto, com unidades multi-familares (ZUM1 e ZUM2). Selecionamos as glebas localizadas ao longo das vias principais (Estradas do Sacarrão, Rio Morto e Bandeirantes), visto que a legislação prevê que ao longo de uma faixa de $100 \mathrm{~m}$ 
para cada lado da via é possível implantar uso misto (residencial, comercial e serviços), com edifícios multi-familiares e gabarito de 6 pavimentos, conforme exemplificado nas Figuras 7 e 8.
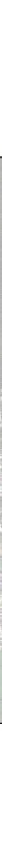

Figuras 7 e 8

Zoneamento Setor E, Estradas do Sacarrão e Rio Morto - Glebas identificadas

Fonte: Desenho elaborado pela equipe SEL-RJ sobre Imagem Geoeye, 2011

A partir da análise acima, procedemos ao estudo dos tipos construtivos adotados pelo mercado imobiliário, realizado com a observação dos lançamentos imobiliários para a área de estudo, relacionado cada tipo com o setor do PEU das Vargens (Figuras 9 a 11). Com isso, estabelecemos os padrões recorrentes e os tipos que utilizamos para as simulações a serem descritas adiante nesse artigo:

- para tipos unifamiliares, casas geminadas com 2 pavimentos e cobertura, com 1 unidade por terreno com $68 \mathrm{~m} 2$ e unidades com $80 \mathrm{~m} 2$ por unidade = média de 4 pessoas por unidade.

- para tipos multi-familiares, edifícios com 12 unidades por pavimento, 72 unidades por bloco, e 790 $\mathrm{m} 2$ de projeção $=$ média de 4 pessoas por unidade. 


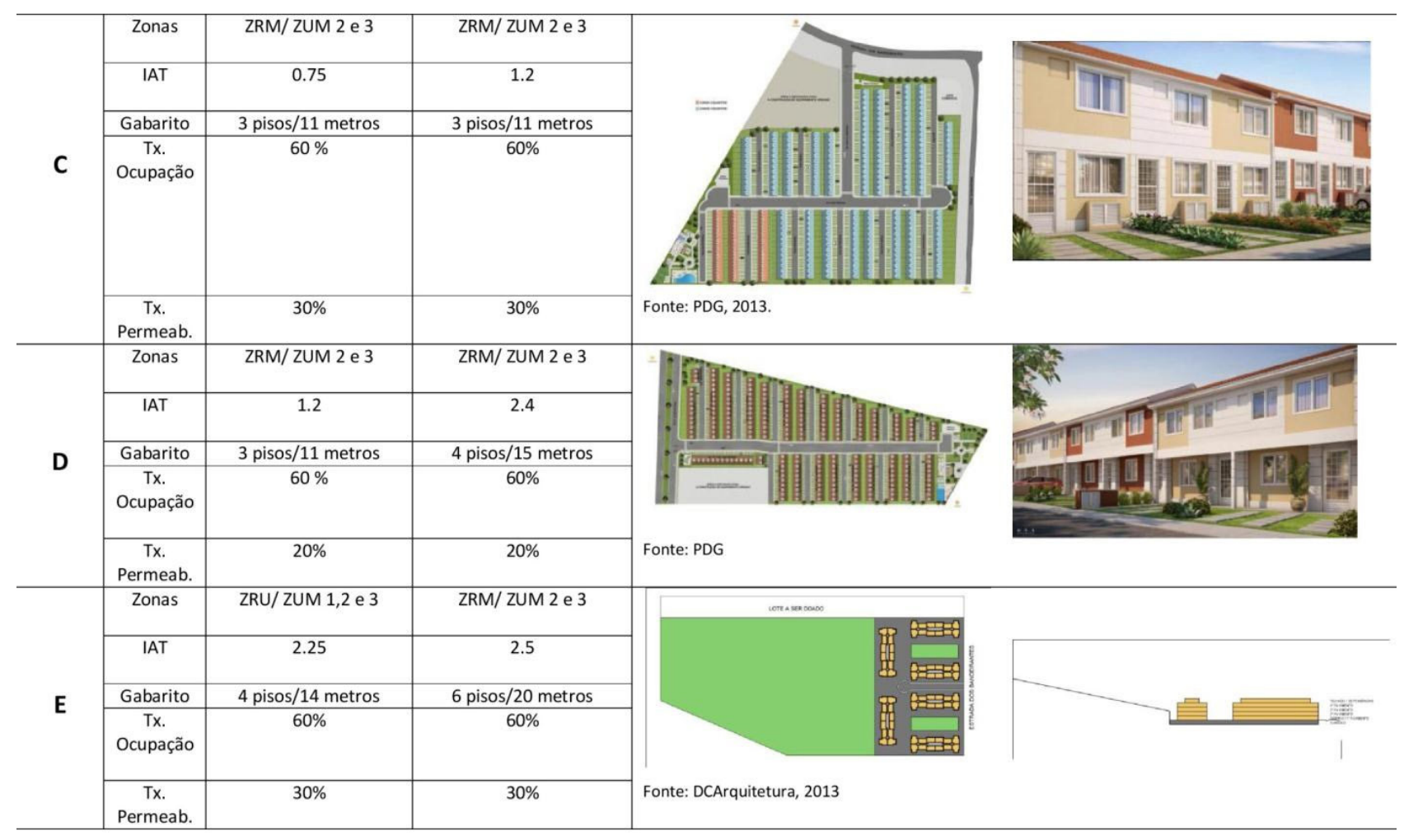

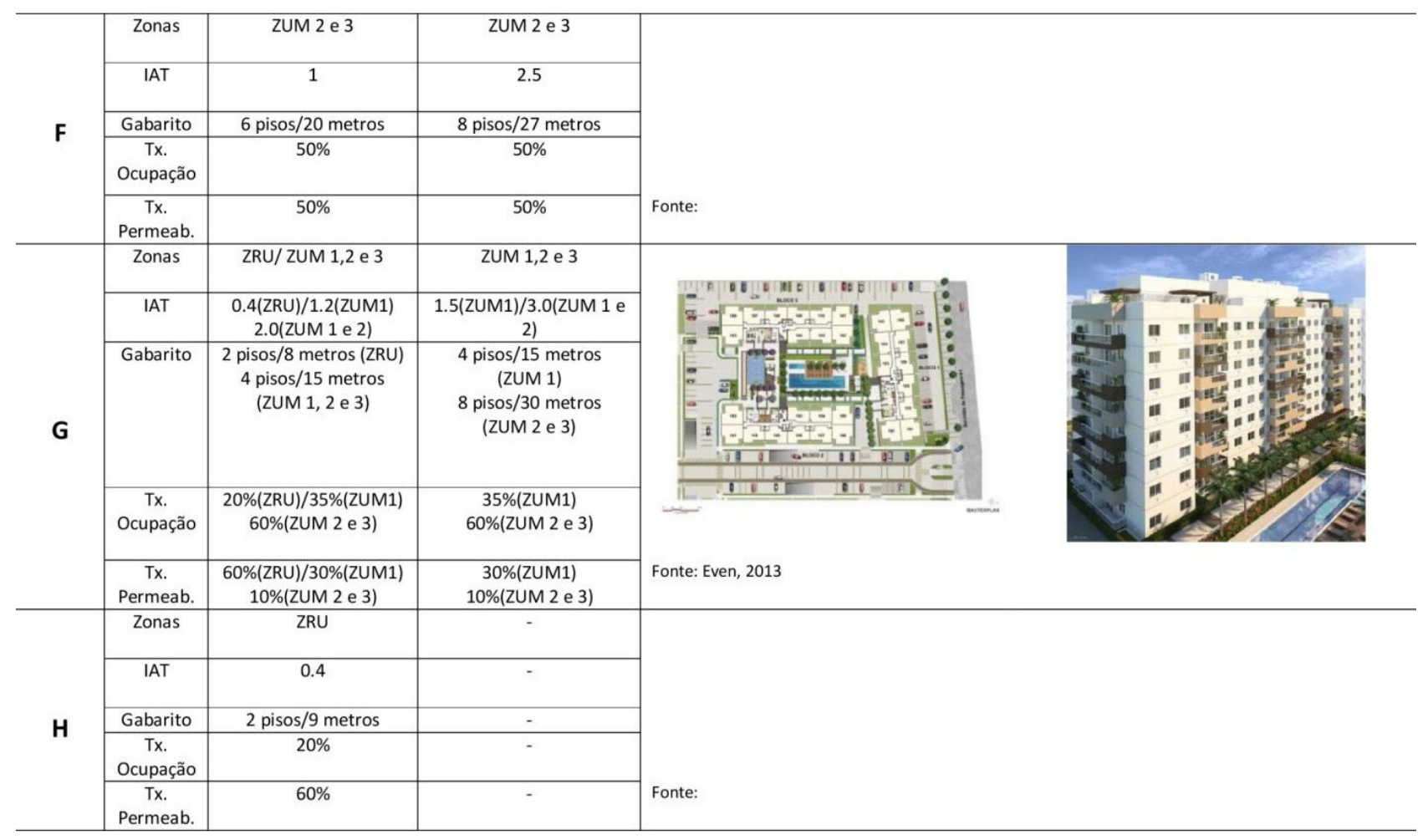

Figuras 9 e 10

Lançamentos imobiliários relacionados a cada setor do PEU 
TIPO: Residência Unifamiliar
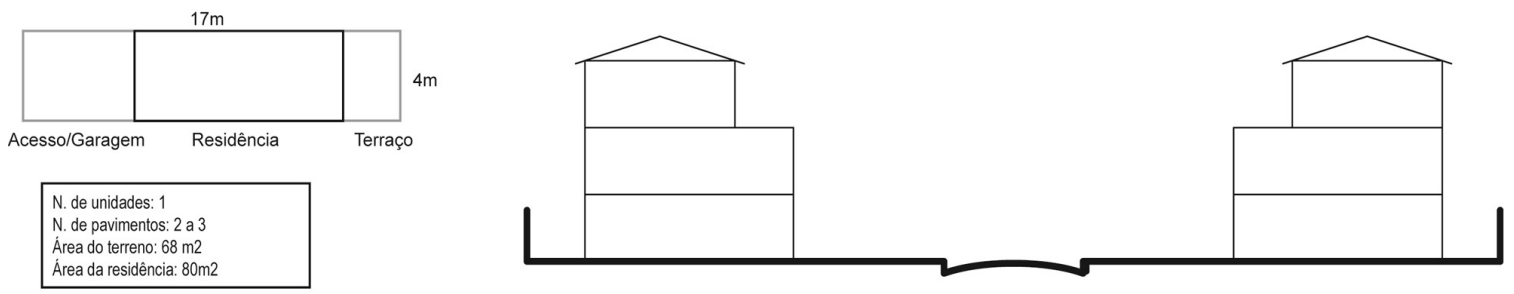

$3^{\circ}$ PAVIMENTO

$2^{\circ}$ PAVIMENTO

TÉRREO $/ 1^{\circ}$ PAVIMENTO

TIPO: Residência Multifamiliar
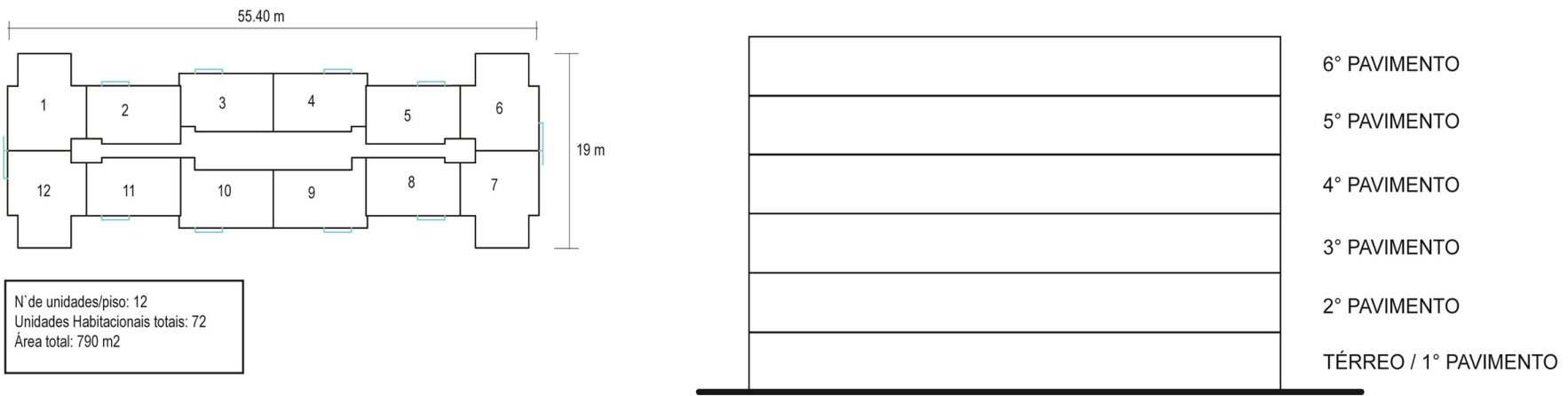

Figura 11

Tipos construtivos definidos para as simulações

Fonte: Desenhos elaborados pela equipe do SEL-RJ sobre Imagem Geoeye, 2011

\section{Cenários e simulações preliminares}

Com base em estudos anteriores sobre a legislação urbanística e a lógica de ocupação e edificação aplicada pelo mercado imobiliário a partir dos parâmetros estabelecidos pelo zoneamento (CARDEMAN e CARDEMAN, 2004), e tendo em vista os investimentos implantados e previstos pelo poder público em resposta às demandas da realização de grandes eventos na cidade, definimos pressupostos para os cenários de curto e longo prazo para as simulações:

\section{Cenário Curto Prazo - até 2016:}

Ocupação das maiores glebas vazias mais a manutenção do existente das ocupações existentes com a doação de 8 a 15\% da área das glebas para uso público - há possibilidade de não fazer a doação através da recompra na Prefeitura desta área, prática pouco utilizada pelos valores cobrados. 


\section{Cenário Longo Prazo - após 2016:}

Renovação urbana: ocupação dos lotes menores, por meio de processos de remembramento e substituição de edificações existentes - casas, sítios e chácaras por condomínios unifamiliares, multifamiliares e mistos.

Observando-se as condições geo-biofísicas da área que apresentam solos inundáveis e com dificuldades para execução de fundações profundas, e considerando a maior lucratividade possível para cada setor, concluímos sobre as premissas para estudo de cada gleba selecionada:

a) doação de área pública de cada gleba será desconsiderada, por se acreditar que em algum momento os 8 a $15 \%$ doados poderão retornar ao mercado, mediante necessidade de arrecadação pela Prefeitura e serem edificados com o potencial previsto em lei;

b) subsolo não será considerado e as vagas obrigatórias serão implantadas no nível térreo, devido às características do solo e com isto o potencial construtivo quase nunca será feito em sua totalidade;

c) atingir máximo possível de pisos previsto em lei;

d) contrapartida prevista em lei sempre será utilizada, significando que o empreendedor poderá obter maior número de pavimentos com o pagamento de taxa para a Prefeitura, conforme previsto pelo Estatuto da Cidade através do instrumento da Outorga Onerosa;

e) ordem de prioridade de usos para simulação seguirá a lógica de rentabilidade: uso apenas multifamiliar; multifamiliar + unifamiliar; comercial/serviço (escritórios) e uso apenas unifamiliar;

f) priorizar o eixo longitudinal que reúne as principais vias de penetração, no sentido floresta à orla, e estudar os transversais significativos, que dão acesso a setores residenciais.

A título de exemplificação, apresentamos nas Figuras 12 a 14 a simulação realizada para três glebas localizadas na Estrada dos Bandeirantes e a transformação prevista: 

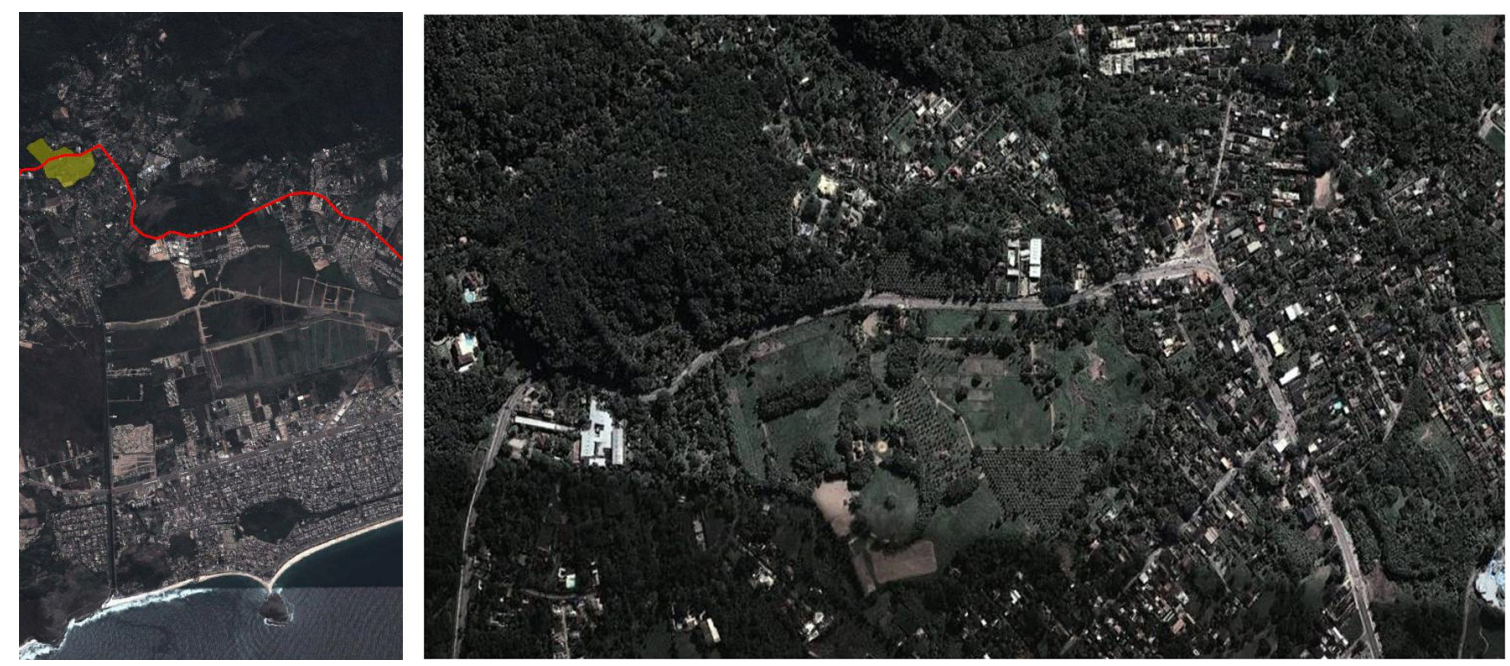

Figura 12

Glebas selecionadas para análise na Estrada dos Bandeirantes

Fonte: Desenhos elaborados pela equipe do SEL-RJ sobre Imagem Geoeye, 2011
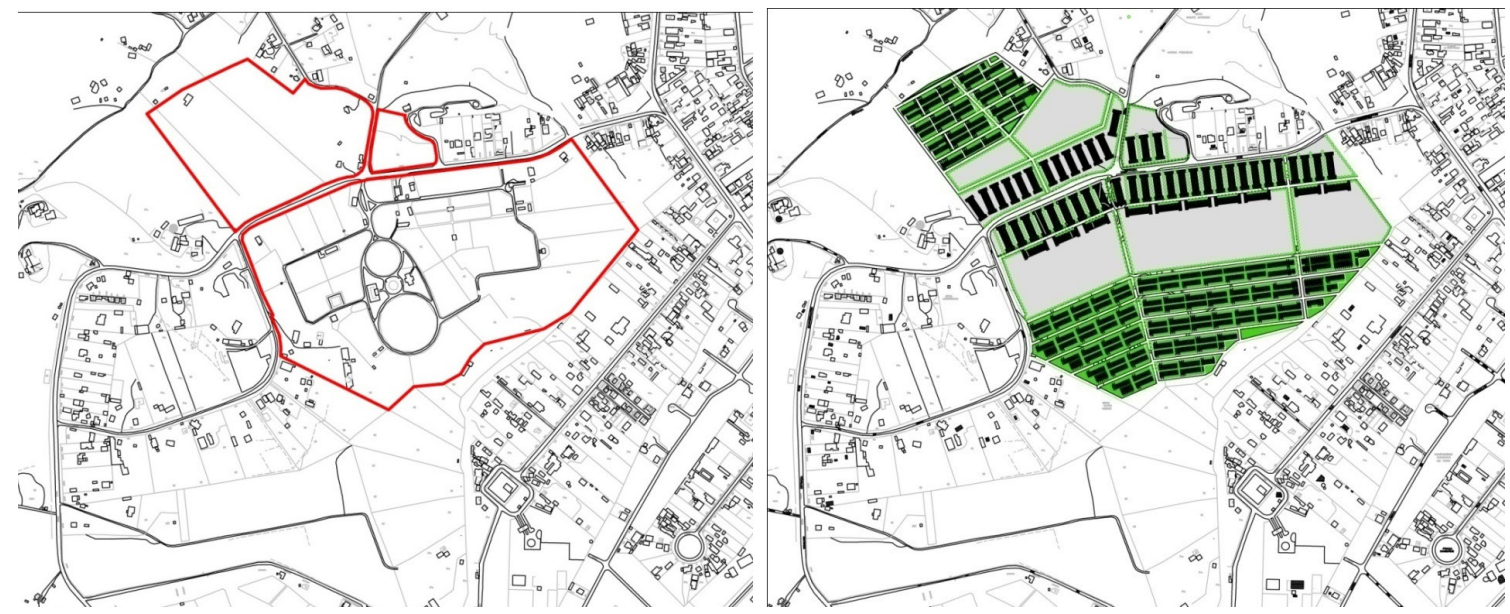

Figura 13

Glebas selecionadas para análise e estudos de implantação

Fonte: Desenhos elaborados pela equipe do SEL-RJ sobre base aerofotogramétrica - PMRJ, 2000

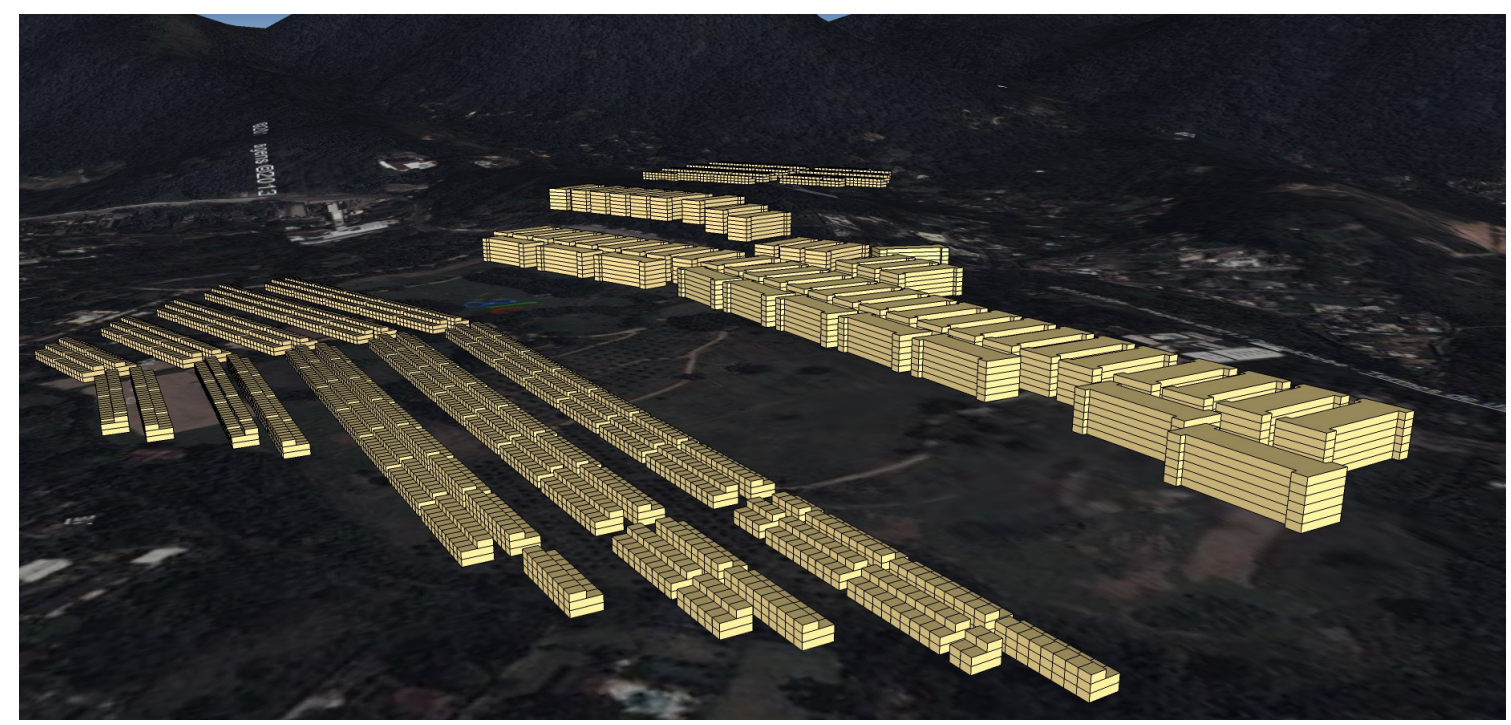

Figura 14

Simulações 3D para as glebas analisadas

Fonte: Desenhos elaborados pela equipe do SEL-RJ sobre mapa Google Earth, 2013 
A Tabela 3 relaciona para cada gleba, a área do terreno e os dados computados em decorrência da simulação: área total construída, área de lazer, área de estacionamento, unidades residenciais multifamilares, unidades residenciais unifamilares, unidades residenciais totais, população total atual estimada e população total simulada.

TABELA 3

Estimativas de cálculo das simulações para Estrada das Bandeirantes

\begin{tabular}{|c|c|c|c|c|c|c|c|c|c|}
\hline Gleba & $\begin{array}{l}\text { Área } \\
\text { terreno } \\
\left(\mathrm{m}^{2}\right)\end{array}$ & $\begin{array}{c}\text { Área total } \\
\text { construída } \\
\left(\mathrm{m}^{2}\right)\end{array}$ & $\begin{array}{l}\text { Área } \\
\text { de } \\
\text { lazer } \\
\left(\mathrm{m}^{2}\right)\end{array}$ & $\begin{array}{c}\text { Área de } \\
\text { estacionamento } \\
\left(\mathrm{m}^{2}\right)\end{array}$ & $\begin{array}{l}\text { Unid. } \\
\text { mult. }\end{array}$ & $\begin{array}{l}\text { Unid. } \\
\text { unif. }\end{array}$ & $\begin{array}{l}\text { Unid. } \\
\text { totais }\end{array}$ & $\begin{array}{l}\text { População } \\
\text { total } \\
\text { simulada }\end{array}$ & $\begin{array}{l}\text { População } \\
\text { total atual }\end{array}$ \\
\hline$\# 1$ & 267910,33 & 29278,84 & 7992 & 66600 & 2664 & 1038 & 3702 & \multirow[t]{4}{*}{15525} & \multirow[t]{4}{*}{15} \\
\hline \#2 & 95088,63 & 10287,16 & 2808 & 23400 & 936 & 321 & 1257 & & \\
\hline \#3 & 11748,49 & 2373,96 & 648 & 5400 & 216 & 0 & 216 & & \\
\hline Total & 374747,45 & 41939,96 & 11448 & 95400 & 3816 & 1359 & 5175 & & \\
\hline
\end{tabular}

\section{Considerações finais}

Até março de 2014, haviam sido realizadas simulações para 294 glebas, totalizando 3.405.799,87 m2 (cerca de 340 ha), 40.833 unidades multi-familiares e 6.995 unidades uni-familiares previstas, com taxas de ocupação varando entre 4 e $60 \%$, dependendo da gleba e do setor do PEU. Cabe ressaltar que os dados obtidos indicam que, via de regra, não se atingiu o Índice de Aproveitamento de Terreno (IAT) máximo permitido pela lei, pelo fato de se estar utilizando parte dos terrenos para alocação de vagas de estacionamento, o que automaticamente reduz a taxa de ocupação e o IAT.

Os dados sobre população estimada para as glebas analisadas indicam um aumento previsto de mais de 33 vezes o tamanho atual, apresentando um aumento de densidade de 11 hab/ha para 402 hab/ha, o que podemos prever acarretará forte pressão por saneamento, abastecimento de água, equipamentos públicos (escola, creche, serviços de saúde, dentre outros) e espaços públicos de lazer e recreação. O que significa que não são apenas os índices de aproveitamento dos terrenos que importam na análise mas os resultados sensíveis para a paisagem, para o ambiente e para a população. 
Em paralelo, demais pesquisadores da equipe estão se dedicando a análises sobre pluviometria, condições micro-climáticas, incidência de vegetação, impactos sobre a paisagem sonora e sobre o ruído urbano. Estão sendo verificados, com esse método, futuros impactos sobre o ambiente urbano, devido às transformações em andamento, em trabalhos em fase de consolidação e a serem publicados após confirmação de dados coletados em campo.

Em conclusão, essa análise pretende contribuir para o estudo aprofundado das características da paisagem de setor urbano em processo de grandes transformações, que acarretam modificações no ambiente social urbano, no desenho da paisagem e na forma de ocupação do território, assim como no perfil da relação entre espaços públicos e espaços privados, aspectos sendo aprofundados pela pesquisa.

Busca-se com esse trabalho fornecer subsídios para formulações normativas e de desenho urbano que possibilitem condições mais adequadas de ocupação, do ponto de vista sócio-ambiental, e que integrem a análise da forma urbana em conjunto com as condições geobiofísicas, da paisagem, do micro-clima e do conforto urbanos. No momento de intensa valorização imobiliária em áreas da cidade que receberão investimentos para os grandes eventos previstos, a pesquisa se justifica pela refletirmos sobre novos instrumentos de legislação urbanística sendo propostos para futuras áreas de expansão.

\section{Agradecimentos}

Os autores agradecem, em nome das equipes envolvidas, o auxílio à pesquisa da FAPERJ e do CNPq. Agradecem também aos bolsistas de Iniciação Científica Gabriel Parreira, Nathalia Possamai, Luiza Baeta Neves, Giselle Sabino, Gabriela Vieira, Marcelo Santos, Luan Rafael Marques de Oliveira e às arquiteta Inês Isidoro e Gabriela Folly que desenvolveram mapas, plantas, simulações e estimativas utilizados nesse artigo. 


\section{Referências}

BUENO, L. M. M.; TÂNGARI, V. R.; SILVA, J. M. P.; PEZZUTO, C. C.; MONTEZUMA, R.; REGO, A. Q. Mudanças climáticas e as formas de ocupação urbana: processo de criação de cenários socioambientais. In: Paisagem e Ambiente, v. 30, 2012. pp. 123 - 136.

CARDEMAN, R.; CARDEMAN, D. O Rio de Janeiro nas alturas. Rio de Janeiro: Mauad, 2004 FORMAN, R.T.T. Land Mosaics. Cambridge: Cambridge University Press: Great Britain, 1995.

FORMAN, R.T.T. Urban Regions - ecology and planning beyond the city, Cambridge: Cambridge University Press, 2008.

MACEDO, S.S. Paisagem, urbanização e litoral. Tese de livre-docência. São Paulo: FAUUSP, 1993.

METZGER, J.P. O que é ecologia de paisagens? In www.biotaneotropica.org.br, publicada em 28/11/2001.

MONTEZUMA, R.C.M; OLIVEIRA, R.R. Os ecossistemas da Baixada de Jacarepaguá e o PEU das Vargens. In: Arquitextos, v. 116, 2010.

NAME, L.P.M.; MONTEZUMA, R. C. M.; SESANA, E.G. Legislação urbanística e produção de riscos: o caso do PEU DAS VARGENS (Rio de Janeiro, Brasil). In: Territorium v. 18, 2011, pp. 201-218.

PEZZUTO, C.C.; SILVA, J. M. P. Método de Análise do Recorte Territorial por meio da Zona Climática e Unidade de Paisagem: Estudo de Caso no Município de Campinas. In: Anais do XII Encontro Nacional e VIII Encontro Latino Americano de Conforto no Ambiente Construído (ENCAC e ELACAC 2013). Brasília: UNB, 2013. pp.1-16.

SCHLEE, M. B. e TÂNGARI, V. R. As montanhas e suas águas: a paisagem carioca na legislação municipal (1937-2000). In Cadernos Metrópole, v. 19, 2008, pp. 271-291. 